\title{
МЕЖДУНАРОДНЫЕ КОНФЛИКТЫ
}

Репьева А.М.

DOI: $10.7256 / 2305-560 X .2014 .4 .12615$

\section{ОСОБЕННОСТИ ПОГРАНИЧНОГО КОНФЛИКТА ИНДИИ И КИТАЯ}

\begin{abstract}
Аннотация: Статья преследует цель осветить исторические предпосылки современных процессов, протекающие в регионах Южной Азии и влияющие на мировой порядок в XXI веке. Политологический анализ урегулирования пограничных конфлликтов в Южной Азии показывает, что существуют шесть региональных особенностей урегулирования пограничных конфликтов, существующих в рассматриваемом регионе: экономическая; политическая; идеологическая; дипломатическая; прецедентная; религиозная особенности. В данной работе внимание сфокусировано на политико-экономической составляющей, влияние которой в большей степени просматривается в данных странах. Основным методом исследования мы выбрали историческую реконструкцию основных событий в приграничных зонах Индии и Китая. В качестве выводов можем указать следующее: урегулирование конфлликта межу КНР и Индией в целом находится в латентной стадии. Изредка проходящие переговоры на высшем уровне лишь обеспечивают стабильность ненападения. При этом реальных шагов по урегулированию пограничного конфликта не предпринимается. Редкие провокации в зоне напряженности служат доказательством того, что стороны не заинтересованы в форсированном и окончательном решении данного вопроса.
\end{abstract}

Ключевые слова: регион, независимость, суверенитет, конфликт, дипломатические отношения, восстание, Индия, Китай, военные действия, внешняя политика.

0 тношения с Китаем традиционно являются одним из приоритетных направлений внешней политики Индии. Они характеризуются перепадами от принципов «панча шила», утвержденных в 1954 году Индией и Китаем, до вооруженных столкновений на границе осенью 1962 года.

После провозглашения независимости Индии в 1947 году и образования КНР 1 октября 1949 года, Индия стала первым несоциалистическим государством, официально признавшим КНР и установившем с ней 30 декабря 1949 года дипломатические отношения. Несмотря на то, что, по выражению Дж. Неру, Индия и Китай являются носителями «полностью противоположных» политических и общественных систем, руководство Индии исходило из необходимости поддерживать с могущественным соседним государством отношения дружбы и сотрудничества, учитывая наличие общей границы протяженностью 2000 км, совпадение целей в их борьбе против колониализма, за национальное возрождение и социально-политические и экономические преобразования.

В июле 1947 года правительство Великобритании и временное правительство Индии сообщили правительству Тибета, что все права и привилегии, которыми обладало правительство
Великобритании, будут переданы правительству независимой Индии. Это обстоятельство имело жизненно важное значение для Индии, учитывая ключевую роль Тибета, с точки зрения обеспечения ее безопасности на восточных и северо-восточных границах. Несмотря на серьезную озабоченность в связи с действиями Китая в отношении Тибета, 12 ноября 1949 года Дж. Неру официально заявил, что Индия «всегда признавала сюзеренитет китайского правительства над Тибетом, но Тибет рассматривался как автономная единица» ${ }^{1}$. После вступления 7 октября 1950 года китайских войск в Лхасу Дж. Неру ограничился подтверждением официальной позиции в отношении Тибета и принял как факт подписание соглашения между пекинскими властями и местным правительством Тибета от 23 мая 1951 года. ${ }^{2}$

Правительство Индии обратилось к руководству Китая с предложением обсудить все касающиеся Тибета вопросы в Пекине или Дели. Начало

\footnotetext{
См.: The Hindustan Times. 1949. 14 November.

2 Манойло А.В. Роль цветных революций в демонтаже современных политических режимов // Национальная безопасность / nota bene. - 2014. - № 3. - C. 104-107. DOI: $10.7256 / 2073-8560.2014 .3 .12058$
} 
этих переговоров в Пекине 31 декабря 1953 года лондонская газета «Таймс» охарактеризовала как «триумф индийской дипломатии» ${ }^{3}$.

Подписание соглашения о торговле и связях с Тибетским районом Китая между Индией и КНР от 29 апреля 1954 года стало кульминацией в утверждении точки зрения Дж. Неру на взаимоотношения с Китаем. Данное соглашение со стороны Индии официально признавало Тибет частью Китая. Документ фиксировал шесть основные пограничных перевалов, что позволило Индии посчитать этот участок пограничным. Индия обязалась передать Китаю, за определенную плату, принадлежащие ей телефонные, телеграфные и почтовые станции, земельные участки и торговые здания. Индия обязалась вывести из пунктов расположения торговых агентств свою военную охрану. Вышеописанные действия вызвали у правящей верхушки Тибета ${ }^{4}$ и оппозиции в Индии негативную реакцию.

После получения власти над Тибетом Китай начал проводить ряд реформ социального характера. Сначала они носили позитивный характер, однако в дальнейшем спровоцировали массовые беспорядки, что вынудило Китай ввести в Тибет войска и начать строительство военной инфраструктуры. В августе 1955 года Китай обвинил Индию в проникновении ее вооруженного отряда на территорию Тибетского района Китая в районе перевала Нити.

Так же большую роль в развитии конфликта сыграла «картографическая агрессия». Китай публиковал карты, на которых около 130 тыс. кв. км Аксай Чина и линии Макмагона были включены в состав Китая. Китайская сторона объясняла это ошибкой в наборе карт, однако начало строительства Синьцзян-Тибетской шоссейной дороги (стратегическое шоссе), проходящей через Аксай Чин, вызвало у Индии решительный протест. ${ }^{5}$

Влияние факторов внешнеполитической обстановки вокруг двух стран, в том числе активное сотрудничество Пакистана с США и Китаем, а так

\footnotetext{
3 Манойло А.В. Технологии управления международными конфликтами на примере революций на Ближнем Востоке и в Северной Африке. // Вестник российской нации. - 2011. №3.

4 Семченков А.С., Бараш Р.Э.Проблема разделенных народов в контексте трансформации мирового политического пространства // Политическая наука. 2009. № 1. С. 137-167.

5 Манойло А.В. Сирийский тупик «Арабской весны». // Вестн. Моск. Ун-та. Сер. 12. Политические науки. 2013. №6. C. 49-56.
}

же развитие двухсторонних отношений между Индией и СССР вызвало дополнительную напряженность в отношениях между двумя странами. Так же на конфликт повлияло событие весны 1959 года - подавление войсками КНР очередного массового восстания в Тибете вынудило Далай-Ламу и 6000 тибетцев бежать в Индию, которая из гуманитарных соображений не могла им отказать. Все это трансформировало китайско-индийские отношения, говоря словами премьера Индии Дж. Неру, в состояние «холодной войны», а из-за последовавших пограничных раздоров она переросла в «горячую» 6 . Конфронтация развернулась за принадлежность территорий Аксай Чина и района в северной части современного штата Аруначал-Прадеш.

Результатом всех этих факторов стало вооруженное столкновение в местечке Лонгджу на индийско-китайкой границе. Далее, в конце октября 1959 года произошел бой в районе перевала Конгка, в ходе которого в плен были захвачены 10 индийских пограничников, 9 из которых позже были убиты. По мнению экспертов, эти два инцидента и стали поворотным моментом в индо-китайских отношениях.

Переговоры и многочисленные личные контакты Дж. Неру с Чжоу Эньлаем не привели к позитивным результатам. Согласно индийским данным, с 1955 по 1962 гг. на индо-китайской границе произошло более 30 вооруженных столкновений. А в результате массированного прорыва китайских войск в районе Тхагла с боевыми действиями в период между 1959 и 1962 гг. КНР дополнительно захватил около 14 тыс. кв. км индийской территории в Аксай Чине. Индийское правительство приняло резолюцию о необходимости освобождения этих земель, которая действует и по сей день. ${ }^{7}$

С 20 по 25 октября 1962 года в общей сложности было убито около 2,5 тысяч индийских военнослужащих (данные о своих потерях китайская сторона не публиковала) ${ }^{8}$. Китайские войска на отдельных расстояниях продвинулись до 100 км вглубь индийской территории. Однако, вопреки ожиданиям КНР, Советский Союз не оказал поддержку своему союзнику по социалистическому блоку и в результате этого, 21 ноября 1962 года, Пекин объявил о начале

\footnotetext{
6 Кузнецов В. КНР - Индия. Трудный путь к взаимопониманию // Азия и Африка сегодня. 2004. №5. С. 2.

7 Манойло А.В. Политические конфликты в международных отношениях и мировой политике. //Мир и Политика. 2013. №2. С. 71-82.

8 Границы Китая: история формирования. М., 2001. С. 319.
} 
одностороннего прекращения огня и отвода войск на 20 км от линии Макмагона. Индия негативно отреагировала на предложение Китая о размещении гражданских постов контроля вдоль линии границы, из-за невозможности военного контроля за территорий. В результате состоявшейся 10 декабря 1962 года в г. Коломбо конференции министров иностранных дел Египта, Камбоджи, Ганы, Индонезии и Бирмы были выработаны предложения о разрешении индо-китайского конфликта. В целом это дало почву для реальной остановки огневого контакта между сторонами, однако за Китаем закрепилось 36 тыс. кв. км территории, которую Индия до сих пор считает своей.

Вышеприведенные события резко активизировали интерес Китая к Пакистану и Кашмирской проблеме. Уже 2 марта 1963 года между Китаем и Пакистаном было подписано пограничное соглашение, которое косвенно обозначало Джамму и Кашмир как пакистанскую территорию, что опять же вызвало протест со стороны Индии. С середины 1960-х и по наше время КНР активно оказывает Пакистану военную и финансовую помощь. Стратегическая составляющая сотрудничества стран отлично выражена в выступлении 3.А. Бхутто в пакистанской Национальной ассамблеи 17 июня 1963 года: «В случае войны с Индией Пакистан не будет одинок. Пакистану окажет помощь самое могущественное государство Азии» ${ }^{9}$.

В 1963 году Индия направила возражение правительствам Китая и Пакистана в связи с началом строительства нового участка стратегического шоссе «Синьцзян-Гилгит», которое проходило на территории Кашмира.

Начало культурной революции в Китае особенно остро сказалось на Тибете ${ }^{10}$, что вызвало новую волну политических и военных противостояний между странами. Китайские спецслужбы активно проводили работу по подготовке сепаратистов из числа индийских племен нага и мизо, проживающих в северо-восточных штатах. Они организовали в пограничных районах центры подготовки сепаратистов.

15 апреля 1976 года, в связи со снижением уровня конфронтации сторон, министр иностранных дел Индии Я. Чаван сообщил в парламенте о решении восстановить дипломатические отноше-

\footnotetext{
9 Границы Китая: история формирования. М., 2001. С. 325.

10 Манойло А.В. Геополитическая картина современного мира // Национальная безопасность / nota bene. - 2013. № 5. - C. 104-107. DOI: 10.7256/2073-8560.2013.5.9394
}

ния с Китаем на уровне послов. КНР поддержал эту инициативу. Однако стабилизация отношений между странами проходила не всегда гладко. Серьезным осложнением в отношении двух стран стали события в Сиккиме в 1973-1975 гг., когда силы, оппозиционные махарадже, обратились к Индии с просьбой принять Сикким в состав республики в качестве 22-го штата. Индия объявила Сикким своей территорией и незамедлительно ввела туда свои военные подразделения, что привело к очередным вооруженным столкновениям.

В результате внутриполитических перемен в обеих странах с середины 1970-х гг. произошло потепление отношений между конфликтующими сторонами. В 1979 году министр иностранных дел Индии А. Ваджпаи прибыл в Китай с официальным визитом. ${ }^{11}$ Однако обсуждение пограничной проблемы, хотя и привело к потеплению двухсторонних отношений, но не дало принципиального разрешения индо-китайского конфликта в целом.

Переговоры по урегулированию пограничного конфликта идут и по сей день. Конфронтация после присоединения штата Сикким к Индии не превышала фазы актуализации ${ }^{12}$, что позволяет вести диалог.

Рассмотрим динамику развития пограничного конфликта Индии и Китая. После ухода Великобритании с континента, отношения между странами были достаточно позитивными, индийская сторона не хотела идти на конфликт и признала за Китаем Тибет. Латентная фаза конфликта начала проявляться в середине 1950-х гг. и достаточно быстро переросла в фазу международного политического кризиса. ${ }^{13}$ C 1959 по 1962 гг. развивалась фаза вооруженного конфликта. Уже в конце 1962 года конфликт перешел на этап активизации.

С активизацией интереса Китая к Пакистану и Кашмирской проблеме ${ }^{14}$ конфликт вернулся на

11 Манойло А.В. Специфика цветных революций «Арабской весны». // Известия Уральск. Федерального Ун-та. Сер. 3. Общественные науки. 2013. №3. С. 30-36.

12 Филиппов В.Р. Буркина Фасо: политический кризис 2011 года // Международные отношения. - 2013. - № 4. - С. 104107. DOI: $10.7256 / 2305-560 X .2013 .4 .9721$

13 Филиппов B.Р. Сердце Черной Африки: запланированный инфаркт // Международные отношения. - 2014. - № 2. - C. 104-107. DOI: 10.7256/2305-560X.2014.2.11643

14 Галочкин В.И. Задачи заключительного тура Международной интернет-олимпиады по информатике и программированию 2012 года для студентов вузов России и ближайшего зарубежья // Программные системы и вычислительные методы. - 2012. - № 1. - С. 104-107. 


\section{Международные конфликты / International Conflicts}

фазу международного политического кризиса, что продолжалось до середины 1970-х гг.. Далее конфликт вернулся на фазу актуализации, где находится и поныне.

Карта конфликта позволяет выявить стороны-участники конфликта и их взаимоотношения. В индо-китайском конфликте принимают участие 5 сторон: Индия, Китай, Пакистан, США, СССР. Между Индией и Китаем отношения конфронтации, США воздействует на Индию, в то же время и на Пакистан, тем самым укрепляет конфронтацию между странами. Пакистан же имеет конфликтные отношения с Индией и союзнические отношения с Китаем. СССР сотрудничал с Индией, а после развала Советского Союза, Россия как его правоприемница пытается восстановить отношения союзников.

Используя древо конфликта мы можем выявить причины, проблемы и последствия индокитайского конфликта. Главной причиной является территориальное притязание обеих стран на Аксай Чин и район в северной части современного штата Арунчал-Прадеш, так же одной из причин можно считать предоставление Индией политического убежища Далай-Ламе и 6000 тибетцам из гуманитарных соображений. Проблемами данного конфликта являются: строительство Синьцзян-Тибетской шоссейной дороги, картографические неточности принадлежности территорий, военное сотрудничество Китая и Пакистана против Индии.
Последствиями конфликта стали вооруженные столкновения Индии и Китая. ${ }^{15}$

Анализ целей, интересов и потребностей раскрывает основную проблему, из-за которой разгорелся конфликт. Со стороны Индии ее потребностью является территориальная целостность. Интересами Индии являются территория в целях сохранения целостности своего государства, и препятствие Китаю в строительстве стратегического шоссе возле индийских границ, а целями - установление сотрудничества с Китаем, которое необходимо обеим сторонам конфликта, ибо полностью удовлетворяет интересы как Индии, так и Китая. Потребности Китая заключаются в доступе и контроле за Тибетом, строительстве на территории Аксай Чина стратегического шоссе. ${ }^{16}$ Интересы Китая заключаются в получении территории для доступа к Тибету и строительства шоссе, а цели в свою очередь связаны с установлением сотрудничества с Индией.

Можно сделать выводы о том, что оба государства видят своей целью сотрудничество. На протяжении почти сорока лет обе стороны активно пытались разрешить создавшуюся конфликтную ситуацию, однако ряд принципиальных вопросов не позволял им это сделать, одним из таких вопросов является сотрудничество Китая с Пакистаном. В разрешении конфликта принимают участие и третьи стороны, что выводит его на международную арену.

\section{Библиография:}

1. Галочкин В.И. Задачи заключительного тура Международной интернет-олимпиады по информатике и программированию 2012 года для студентов вузов России и ближайшего зарубежья // Программные системы и вычислительные методы. - 2012. - № 1.

2. Границы Китая: история формирования. М., 2001.

3. Кузнецов В. КНР-Индия. Трудный путь к взаимопониманию // Азия и Африка сегодня. 2004. №5. С. 2.

4. Манойло А.В. Роль цветных революций в демонтаже современных политических режимов // Национальная безопасность / nota bene. - 2014. - № 3. DOI: 10.7256/2073-8560.2014.3.12058

5. Манойло А.В. Технологии управления международными конфликтами на примере революций на Ближнем Востоке и в Северной Африке. // Вестник российской нации. - 2011.-№3.

6. Манойло А.В. Сирийский тупик «Арабской весны». // Вестн. Моск. Ун-та. Сер. 12. Политические науки. 2013. №6. C. 49-56.

7. Манойло А.В. Политические конфликты в международных отношениях и мировой политике. //Мир и Политика. 2013. №2. С. 71-82.

8. Манойло А.В. Геополитическая картина современного мира // Национальная безопасность / nota bene. - 2013. № 5. DOI: 10.7256/2073-8560.2013.5.9394

\footnotetext{
15 См.: Филиппов В.Р. Национально-культурная автономия: классическая концепция и ее современная интерпритация// Национально-культурная автономия: проблемы и суждения. Сер. «Этнодиалоги», Москва, 1998. С. 63-84.

16 Манойло А. В. Парадигмы управления международным конфликтами: конкуренция или конфронтация // Национальная безопасность / nota bene. - 2011. - № 5. C. 104-107.
} 


\section{Международные отношения / International Relations / № 4/2014}

9. Манойло А.В. Специфика цветных революций «Арабской весны». // Известия Уральск. Федерального Ун-та. Сер. 3. Общественные науки. 2013. №3. С. 30-36.

10. Манойло А. В. Парадигмы управления международным конфликтами: конкуренция или конфронтация // Национальная безопасность / nota bene. - 2011. - № 5 .

11. Семченков А.С., Бараш Р.Э.Проблема разделенных народов в контексте трансформации мирового политического пространства // Политическая наука. 2009. № 1.

12. Филиппов B.P. Буркина Фасо: политический кризис 2011 года // Международные отношения. - 2013. - № 4. DOI: 10.7256/2305-560Х.2013.4.9721

13. Филиппов B.P. Сердце Черной Африки: запланированный инфаркт // Международные отношения. - 2014. - № 2. DOI: $10.7256 / 2305-560 X .2014 .2 .11643$

14. Филиппов В.Р. Национально-культурная автономия: классическая концепция и ее современная интерпритация// Национально-культурная автономия: проблемы и суждения. Сер. «Этнодиалоги», Москва, 1998.

\section{References (transliterated):}

1. Galochkin V.I. Zadachi zaklyuchitel'nogo tura Mezhdunarodnoi internet-olimpiady po informatike i programmirovaniyu 2012 goda dlya studentov vuzov Rossii i blizhaishego zarubezh'ya // Programmnye sistemy i vychislitel'nye metody. 2012. - № 1.

2. Granitsy Kitaya: istoriya formirovaniya. M., 2001.

3. Kuznetsov V. KNR-Indiya. Trudnyi put' k vzaimoponimaniyu // Aziya i Afrika segodnya. 2004. №5. S. 2.

4. Manoilo A.V. Rol' tsvetnykh revolyutsii v demontazhe sovremennykh politicheskikh rezhimov // Natsional'naya bezopasnost' / nota bene. - 2014. - № 3. DOI: 10.7256/2073-8560.2014.3.12058

5. Manoilo A.V. Tekhnologii upravleniya mezhdunarodnymi konfliktami na primere revolyutsii na Blizhnem Vostoke i v Severnoi Afrike. // Vestnik rossiiskoi natsii. - 2011.-№3.

6. Manoilo A.V. Siriiskii tupik «Arabskoi vesny». // Vestn. Mosk. Un-ta. Ser. 12. Politicheskie nauki. 2013. №6. S. 49-56.

7. Manoilo A.V. Politicheskie konflikty v mezhdunarodnykh otnosheniyakh i mirovoi politike. //Mir i Politika. 2013. S. 71-82.

8. Manoilo A.V. Geopoliticheskaya kartina sovremennogo mira // Natsional'naya bezopasnost' / nota bene. - 2013. - № 5. DOI: $10.7256 / 2073-8560.2013 .5 .9394$

9. Manoilo A.V. Spetsifika tsvetnykh revolyutsii «Arabskoi vesny». // Izvestiya Ural'sk. Federal'nogo Un-ta. Ser. 3. Obshchestvennye nauki. 2013. №3. S. 30-36.

10. Manoilo A. V. Paradigmy upravleniya mezhdunarodnym konfliktami: konkurentsiya ili konfrontatsiya // Natsional'naya bezopasnost' / nota bene. - 2011. - № 5.

11. Semchenkov A.S., Barash R.E.Problema razdelennykh narodov v kontekste transformatsii mirovogo politicheskogo prostranstva // Politicheskaya nauka. 2009. № 1.

12. Filippov V.R. Burkina Faso: politicheskii krizis 2011 goda // Mezhdunarodnye otnosheniya. - 2013. - № 4. DOI: 10.7256/2305-560X.2013.4.9721

13. Filippov V.R. Serdtse Chernoi Afriki: zaplanirovannyi infarkt // Mezhdunarodnye otnosheniya. - 2014. - № 2. DOI: 10.7256/2305-560X.2014.2.11643

14. Filippov V.R. Natsional'no-kul'turnaya avtonomiya: klassicheskaya kontseptsiya i ee sovremennaya interpritatsiya// Natsional'no-kul'turnaya avtonomiya: problemy i suzhdeniya. Ser. «Etnodialogi», Moskva, 1998. 